\title{
La configuración de la Vida Cotidiana en familias con niños o niñas diagnosticados con Trastorno Generalizado del Desarrollo (TGD) y/o Trastorno del Espectro Autista (TEA)
}

\section{Dana Elina Godoy}

Licenciada en Trabajo Social (Universidad Nacional de Entre Ríos)

Maestranda en Maestría en Salud Mental Social (Universidad Nacional de Entre Ríos)

Correo: godoydanaelina@gmail.com 


\section{Resumen}

El propósito de este trabajo es recuperar algunas claves de la investigación ${ }^{131}$ que realicé en la Facultad de Trabajo Social de la Universidad Nacional de Entre Ríos. La misma fue dirigida por la Magíster en Trabajo Social María Alfonsina Angelino y tuvo como objeto de estudio "La configuración de la Vida Cotidiana en familias con niños o niñas diagnosticados con Trastorno Generalizado del Desarrollo (TGD) y/o Trastorno del Espectro Autista (TEA)”. La elección de estos diagnósticos respondió a la masificación de los mismos en la actualidad y a su irrupción en la infancia. Este trabajo apuntó a conocer y analizar las rupturas y continuidades que se manifestaron en la cotidianeidad de la familia a partir del diagnóstico de su hijo. A fin de responder a este objetivo, realicé una investigación de tipo cualitativa que me permitió analizar e interpretar no solo las tres entrevistas en profundidad realizadas a madres de niños diagnosticados con TGD y/o TEA, sino también las charlas informales al interior del Grupo TGD Padres Santa Fe, la asistencia a reuniones y las observaciones. La hipótesis que sostuve fue que la vida cotidiana en las familias se encontró modificada a partir del diagnóstico, volviéndose estructurada, reglada y terapéutica. No solo ello quedó evidenciado durante todo el trayecto de este trabajo, sino que también pude advertir las nuevas prácticas cotidianas que empezaron a formar parte de la familia a fin de responder a los tratamientos que necesitan sus hijos.

\section{Palabras clave}

vida cotidiana, familia, diagnóstico

131 Dicha Investigación, correspondiente a la Licenciatura en Trabajo Social, fue defendida el 17 de octubre del año 2017 en la Facultad de Trabajo Social. Paraná, Entre Ríos.

\section{Abstract}

The purpose of this work, is to recover some keys of the investigation that I made in the Faculty of Social Work at the National University of Entre Rios. It was directed by the Magister in Social Work María Alfonsina Angelino and had as object of study "The configuration of the daily life in families with kids that has been diagnostic with generalized disorder of developing or autism spectrum disorder". The selection of this diagnoses respond to a current situation: its massification and irruption in childhood. This work aimed to discover and analyze the ruptures and continuities that manifested in the daily life of the family after their child's diagnosis. In order to achieve this objective, I conducted a qualitative research that allowed me to analyze and interpret three in-depth interviews with mothers of children diagnosed with TGD and / or ASD, informal talks within the TGD Group Parents Santa $\mathrm{Fe}$ and meetings attendance and observations. The hypothesis held was that the daily life of families was modified once given the diagnosis, becoming structured, regulated and therapeutic This was evidenced throughout the course of this work and I could also notice the new daily practices that began to be part of the family in order to respond to the treatments that their children need.

\section{Keywords}

daily life, family, diagnoses 


\section{Introducción}

Actualmente vivimos en una sociedad en la que se advierte una multiplicidad de nuevos diagnósticos psicopatológicos que desde hace un tiempo clasifican a la infancia. En palabras de Juan Vasen, se clasifica a los niños en función de cierta lectura de aquellas conductas y rendimientos que se consideran trastornados. Se les ponen nombre a esos trastornos, nombres que pasan a ser nuevas palabras maestras (2011:20). Según el autor,

Entonces la sensibilidad se abomba y ya no pensamos en qué le pasa a un niño, sino en qué tiene; no pensamos en un quién, sino en un qué. Esta desensibilización lleva a etiquetar y hallar siglas que son pobres nombres para problemas de época que estallan en las aulas y los hogares. Siglas que nombran síndromes que se desentienden de los nuevos rasgos de los niños de hoy, de lo movedizo del piso en que pretenden afirmarse padres y maestros, de los cambios en la cultura, la temporalidad de los encantos del consumo y la desorientación de las escuelas (Vasen, 2011:37).

El mismo autor nos dice que no hay duda de que un buen diagnóstico alivia muchas incertidumbres y puede aclarar ciertas lógicas que subtienden una situación sufriente. Pero oscurece cuando descarrila y queda reducido a una técnica clasificatoria que tiende a convertir lo histórico y situacional en algo que simplemente es. Esta tendencia tecnocrática a objetivar suele recortar una existente desgajándolo de la trama de relaciones en que surge. En esta misma línea, me parece interesante tomar los aportes de Angelino Alfonsina (2014) en relación a lo cuidados de la familia, específicamente cuando hace mención a que en lo cotidiano entran en escena una multiplicidad de prácticas profesionales de la rehabilitación que se ocuparán de cuidar a ese niño o niña. Aquello que hay que hacer aun cuando el niño o niña no quiera o se canse o resista. Hay que hacer lo que el médico dijo o recetó.

Sobre la base de estas ideas comencé a interrogarme acerca de los diagnósticos en los niños y niñas, específicamente, en los cambios 
que se producen a partir de los mismos, no solo en su vida cotidiana sino también en la de su familia. Comencé a pensar en la estructura que tendrían las nuevas actividades y como este niño o niña junto a su familia se organizarían de allí en más; como serían sus tiempos, sus lugares, sus responsabilidades y exigencias, sus sentimientos y actitudes frente a un diagnóstico. Me pregunté si su vida cotidiana se encontró modificada, estructurada y organizada de diferente manera a partir de los tratamientos y terapias a los que el niño/a debe asistir reconociendo que "la batalla contra el tiempo es una de las tantas recomendaciones de los profesionales" (Angelino, 2014:76).

Es por ello que el problema de investigación que decidí indagar fue: "La configuración de la Vida Cotidiana en familias con niños o niñas diagnosticados con Trastorno Generalizado del Desarrollo (TGD) y/o Trastorno del Espectro Autista (TEA)", por tanto los interrogantes centrales que organizaron este trabajo de investigación rondaron en torno a cuáles son las reacciones y acciones en cada familia en relación a la emergencia del diagnóstico, cómo, a partir de allí, se ordena y organiza esa vida cotidiana y cómo se distribuyen las tareas para dicha organización.

Centrarme en el momento en que este niño/a fue diagnosticado me permitió registrar la organización de la vida cotidiana no sólo del niño/a si no, de los otros integrantes de la familia que se adaptan a la distribución de tareas propuestas por la agenda de éste/a que se vuelve estructurada, reglada y terapéutica porque, el niño o niña diagnosticado/a tiene actividades, no solo terapéuticas pautadas y regladas sino también aquellas que corresponden al juego y la recreación.

\section{Desarrollo}

Tomar la categoría de Vida Cotidiana me permitió no solo analizar e interpretar la subjetividad de los actores involucrados, sino que también pude reconocer los significados que estos le dieron tanto a su pasado como a su situación actual. En función de ello advertí en la necesidad de recuperar la palabra de la familia, siendo ésta el instru- 
mento para analizar sus experiencias, sus pensamientos, sus sentidos y sus valores que se han modificado y que tal como plantea Angelino Alfonsina (2014) los padres quedan suspendidos en su papel de decisores y solo ejecutan lo que los profesionales indican. En tal sentido, toda práctica, todo juego será terapéutico y en clave de tratamiento, porque al decir de la autora "el discurso médico va marcando el rumbo y las trayectorias que deberán cumplir el discapacitadx y quién se ocupe de él/ella en la búsqueda de la normalización y/o rehabilitación” (2014:198).

Dicha investigación, que fue de tipo cualitativa, me permitió la interpretación y el análisis de la configuración de la vida cotidiana en familias con niños o niñas diagnosticados con TGD y/o TEA. La elección se debió a que, en la Investigación Cualitativa "el investigador estudia a las personas en el contexto de su pasado y de las situaciones en las que se hallan" (Taylor y Bogdan, 1987:20), relacionándose ello estrechamente al objeto de Investigación, ya que lo que interesó fue conocer cómo se configura la vida cotidiana en las familias y si ella se encontró modificada a partir del diagnóstico.

\section{La reconstrucción de la experiencia}

Los encuentros con estas mujeres ${ }^{132}$ se dieron en el marco de una entrevista abierta y en profundidad. Al tratarse de su experiencia frente al diagnóstico de sus hijos/ hijas lo que ellas hicieron fue una reconstrucción de su vida a partir del mismo. En dicho sentido estas mujeres se sumergieron en recuerdos, sentimientos y emociones de ese pasado, aspirando a que la narración esté conectada y sea interpretada tanto por mí, como investigadora, como por ellas protagonistas de la misma.

Siguiendo este planteo presento a continuación algunos fragmentos de los relatos que estas mujeres me brindaron, los cuales, me permitieron, sin duda, acercarme a su vida cotidiana, reconociendo a su

132 Si la vida cotidiana se modifica y re organiza con la llegada de un hijo, el advenimiento de un diagnóstico es un punto de inflexión en esa organización que coloca en el centro a la mujer-madre. Es así que, en dicho trabajo realicé entrevistas en profundidad a tres madres de niños diagnosticados con TGD y/o TEA. Asimismo, participé de charlas informales y reuniones al interior del Grupo TGD Padres Santa Fe. 
vez los tiempos y espacios en los que desarrollaron las estrategias y procedimientos para la organización de la misma.

\section{La rigurosa cotidianeidad de Marina}

A través de una amiga en común, conocí a Marina, madre de Tobías de 5 años de edad, diagnosticado con TGD. Marina es oriunda de Crespo, Entre Ríos, pero muchos años residió en la Ciudad de Córdoba, incluso los primeros años de vida de Tobías. Luego, con diagnóstico en mano decidieron junto a su pareja trasladarse nuevamente a su lugar de origen, para que el niño no sea un paciente más $y$ esté más cerca de su familia.

A Marina la percibí tranquila, quizás ese estado respondía a que su vida se encuentra organizada y estructurada para que el tratamiento de Tobías funcione perfectamente. Tal es así que tanto en la casa como en el jardín y en las terapias, Tobías tiene una agenda donde dice que va a suceder durante el día. Es ella quien se encarga de fotografiar los juguetes de Tobías para luego incluir dichas imágenes en un catálogo de fotos, que se convierte en una herramienta indispensable para el desarrollo del PECS, sistema de intercambio de imágenes, para desde allí trabajar en las terapias tal como lo sugiere el Centro Médico Especializado en Autismo donde evalúan una vez por año el tratamiento de Tobías.

Tobías comenzó con su tratamiento a los dos años, a él lo diagnosticaron en noviembre y, en marzo del año siguiente ya tenía un jardín en donde sabian que él tenía TGD, que tenía que ir con una maestra integradora. Aquí no puedo dejar de referirme a lo que plantea Gisela Untoiglich (2009) cuando hace referencia a los diagnósticos, problematizándolos de la siguiente manera: que ocurriría si, mientras un pequeño está estructurándose, un profesional dictamina, por ciertas conductas observables, que este niño “es...” ADD, TGD, o cualquiera de las siglas que abundan en el Manual. Probablemente su subjetividad se fijaría en esa etiqueta. Padres y docentes también comenzarían a esperar que el pequeño se comportara de determinada manera y todos los argumentos se cerrarían sobre sí mismo, "hace esto porque es ADD”, “todos los TGD responden así”, etc. Podría incluso ocurrir 
que el propio niño se ubicara en el casillero correspondiente y ya no esperara otra cosa de sí mismo, no pudiendo conectarse con aquello que le sucede más allá de la sigla.

Marina me contó que lo primero que hacen es informarles a los padres de los compañeros que Tobías es así, que no es que él no quiere jugar, sino que tenes que mirarlo, agarrarlo, que no es que él no quiere ser amigo de los chicos sino que tienen que ir de otra manera, que cada uno le explique a sus hijos como pueda. En este sentido, me parece interesante tomar los aportes de Indiana Vallejos quien trabaja la de idea de "la diferencia de los diferentes" que es cuando se destaca que esos sujetos están incompletos, disminuidos: escucha poco, ve poco, habla mal, piensa poco y aprende mal, reconociendo que "construir al discapacitado como diferente exalta el déficit y lo constituye en un estigma social que afecta e invade no solo al sujeto que lo porta sino también aquellos con quienes se relaciona, especialmente la familia y más específicamente a la madre” (2005:75).

\section{La casa, el jardin y las terapias}

Marina, insiste en que se trabaje con el PECS. El mismo tiene que ver con la comunicación aumentativa, entonces, por ejemplo, Tobias tiene en la casa, en el jardín y en las terapias una agenda donde dice que va a suceder todo el tiempo, son anticipadores visuales. En tal sentido y, recordando el día en que le dijeron que tenía que trabajar de esa manera, reflexionó que en realidad es una pavada, la agenda es la misma todos los días, cambian ciertas cosas, todos los dias te levantas, desayunas, todos los días almorzás, todos los días preparas la mesa; le muestro la fotito "preparar la mesa" y ya está... Aquí puedo notar que la organización de la agenda de Tobías es parte de la cotidianeidad en la familia, y que, tal como lo mencionó al inicio del encuentro, el diagnóstico de Tobías no los puso mal, solo sintieron que tendrían que trabajar más.

El traslado de la familia hacia la ciudad de Crespo resultó una modificación en su cotidianeidad. Marina me contó que cuando vivían en Córdoba trabajaba afuera de su casa y junto a su pareja se iban turnando para concurrir a las terapias de Tobías. Luego, cuando 
deciden mudarse, ella dejó de trabajar para dedicarse a él, porque él todo el tiempo tiene que estar con alguien, necesita estimulación. Tal es así que, durante el encuentro pude observar cómo ante cada pedido de Tobías, Marina pidiéndome disculpas, se levantaba e iba corriendo hacia donde estaba el niño. Aquí, considero interesante tomar las palabras de Alfonsina Angelino (2014) quién plantea la idea de que en discapacidad, el cuidado -sobre todo materno- es cuidado vigilado. Resulta un cuidado bajo vigilancia por el modelo médico y la ideología de la normalidad. Pero es una vigilancia fundamentalmente orientada al accionar de la madre o a quien cumpla la función maternal. La autora considera que aquí opera también el dispositivo moralizante que configura la noción de buena madre que cuida de sus hijxs, sobre todo si son discapacitadxs.

\section{Laura, una mamá animada}

Al momento de la investigación Laura tenía 42 años, su hijo Sebastián 18 y Leandro 13, éste último diagnosticado con Síndrome de Asperger.

\section{Avanzar y Retroceder}

Leandro fue diagnosticado con Trastorno Generalizado del Desarrollo al comenzar su segundo grado, donde según Laura él empieza a avanzar y retroceder. Fue su maestra, que tenía un familiar TGD, quién vio algunas características en Leandro. A partir de allí primero fue la psicopedagoga quién le dijo que no tenía nada, que las actividades las realizaba, hasta que empezó a darse cuenta de que a la clase siguiente Leandro se había olvidado, o al par de horas, tenía que explicarle nuevamente. Luego fue el Neurólogo. Respecto de la visita a éste, Laura me contó que el profesional al cabo de dos sesiones le dice que Leandro tenía Trastorno Generalizado del Desarrollo (TGD) y que necesitaba de medicación, siendo que él no había observado al niño. Ante esta situación Laura se opone y pide al profesional los fundamentos de tal indicación, resaltando la personalidad de Leandro y demostrándole que su hijo no necesitaba tomar medicamentos. Ante ello el medico les dijo "bueno no lo vamos a medicar" 
y decide llevar a cabo un estudio con una psicopedagoga o psicóloga, que trabaja junto con él, la que le hace los test. Aquí, se puede observar la posición de poder que frente al médico/profesional instauró Laura y, de la cual nos habla Alfonsina Angelino (2014) reconociendo la necesidad que tienen estas mujeres al acceso a la información y la necesidad de que como madres se socialicen los recorridos, trayectos, los mejores tratamientos, los profesionales más humanizados.

Laura recordó que al cabo de 4 o 5 sesiones, les dieron el resultado, las palabras fueron: "tu nene tiene TGD”, ¿qué es eso? es como un autismo. Ante dicho diagnostico la pregunta que como padres se hicieron fue: ¿ahora qué hacemos?, manifestando que quedaron helados ante tal noticia y que los profesionales le sugirieron que buscaran algún centro, alguna psicóloga que lo vea. Aquí, Laura resaltó la actitud que tuvo el médico hacia ellos, éste no tuvo la sensibilidad de decirles: mire papá con esto no se acaba el mundo. Laura, no se sintió acompañada por el profesional, ya que, para ella el neurólogo tendría que tener dos o tres centros para sugerir a los padres en donde puedan seguir el tratamiento de sus hijos, porque tal como mencioné más arriba, luego del diagnóstico del niño los padres se encuentran en la necesidad de buscar el tratamiento de rehabilitación más adecuado para su hijo, en el que no solo participa el Estado a partir del despliegue de las distintas políticas públicas orientadas a la discapacidad, sino que también aparece el mercado ofreciendo una multiplicidad de servicios a quienes quieran y puedan comprarlos (Angelino, 2014).

Una vez que tuvieron el diagnóstico de Leandro, Laura me contó que comenzaron a buscar una Escuela a la cual él pudiera concurrir, tomando la recomendación de que tenía que tener un grupo no tan grande en el aula, para que él pueda entender. A su vez les habían hablado de maestra integradora, pero era un lio conseguirla. Por tal motivo, inscribieron a Leandro en un Colegio de Sauce Viejo, donde ellos vivían en ese momento, era una escuela tipo de campo, que son primero y segundo juntos, tercero y cuarto juntos, eran entre los dos grados 10 chicos, 15 como mucho, dijeron es lo ideal.

Una vez comenzadas las clases, la escuela tomó más alumnos y entonces, él en lugar de estar con chicos de primero, segundo y ter- 
cero, está con chicos de cuarto y quinto. Fue allí donde según Laura comienzan los problemas, él no quería hacer nada y vivía en la dirección; la maestra lo mandaba con la directora con un banquito al costado y le daban lápices de colores y hojas. Aquí Laura sintió la necesidad de ir a hablar con la maestra llegando, incluso, a ofrecerse como maestra auxiliar considerando que ella sabía cómo había que tratar a su hijo, reconociendo que él no era un niño molesto y que era la docente quién debía imponerse para que él realice las actividades. A su vez, afirmaba que a Leandro no podía darle una evaluación como a cualquier otro chico, sino que la docente tenía que hacer una adaptación curricular, que por lo que argumenta Laura, ella no lo estaba haciendo. Aquí, nuevamente puedo observar cómo Laura se impuso como madre, en palabras de Angelino (2014) custodiando del cumplimiento en cantidad y calidad de todos los mandatos de normalización y rehabilitación que requiere el diagnóstico y el pronóstico.

Como resultado de ello y al finalizar el año, Leandro no solo había perdido dos o tres meses en la Escuela por una enfermedad por la cual había estado internado, sino que, a su vez, Laura se había enterado que lo dejaban de lado, siendo ello lo que la motivó a buscar otra Escuela para su hijo. Teniendo conocimiento sobre cómo era el funcionamiento de La Salle Jobson en la capital santafesina, insistió para que dicha institución tenga en cuenta a Leandro, y, fue allí donde comenzó su $3^{\circ}$ grado. En esta Escuela funciona “durante el turno tarde una propuesta educativa para aquellos alumnos de Nivel Primario y Secundario que no encuentran un lugar para aprender constituyéndose como un espacio educativo de contención y acompañamiento a niños y jóvenes con necesidades educativas especiales"; estas palabras de presentación de la Escuela fueron extraídas desde su página web ya que, la explicación de Laura no me fue suficiente para entender el funcionamiento de dicha institución. Considero que esta propuesta remite a lo que plantea Indiana Vallejos (2015) en "Parecerse a Nosotros" respecto de que consecuentemente, es imperativo suavizar las denominaciones, que tienen una impronta de liviandad que alivia (al que nombra) y de máscara que enmascara (al que es nombrado). 
La discapacidad se torna "capacidades diferentes", "necesidades educativas especiales" y se oculta tras esas denominaciones.

\section{María Eugenia y su protección a Lorenzo}

María Eugenia es madre de Lorenzo, quien al momento de la entrevista estaba por cumplir 8 años. Lorenzo fue diagnosticado con autismo entre los dos años y medio y los tres, pero María Eugenia se había dado cuenta antes, más precisamente desde su nacimiento. Ella es docente de Educación Musical y hasta cuando hizo referencia a su profesión habló de autismo y de las luchas diarias que como docente y como mamá realizó respecto de la integración y la inclusión de los niños con discapacidad, porque ella quiere aliviarles el camino a muchas madres que viven situaciones como la que ella atravesó, reconociendo que la solución no es ir cambiando a los niños de escuela porque vas a tener el mismo estrés o peor, sino que todos tengan el mismo lenguaje, que se hable de inclusión y que se escuche a los padres para saber cómo se puede trabajar con el niño.

María Eugenia dice que ella se dio cuenta desde que nació y que al año y medio se dijo -a sí misma- que tenía autismo, porque cuando Lorenzo nació no se prendía de la teta, o si se prendía era un ratito y no la miraba. Ella ya sabia, se le caían las lágrimas porque quería escuchar otra cosa y no Autismo. Cuando el neurólogo le dio el diagnostico le dio un papel para llenar de discapacidad. Ella no quería llenar nada, se negaba a la palabra discapacidad, que tenés un montón de beneficios, pero qué te importan los beneficios, en ese momento lo que querés es un hijo, por decirlo así, neurotípico normal. Se le caían las lágrimas, pero no era una noticia nueva, ella ya lo sabía.

En palabras de María Eugenia cuando te dicen Diagnóstico, se te derrumbó la vida, se te derrumbó todo. Tenés que organizarlo a él y después organizarte vos. Pero, según ella, todas pasan por ese camino lleno de piedritas y de angustia. Te vas cayendo, pero luego te levantas y te curas. A su vez, sino fuera que el tiempo transcurrió, ella no me lo podría contar, estaría llorando y, cuando ese dolor des- 
apareció y querés seguir luchando, ahi estas preparada para ayudar al otro.

En María Eugenia, al igual que en Laura, también se presentó la idea de "ayudar al otro", ese otro con el cual comparte las mismas experiencias y sentimientos y con el cual va a empezar a tejer una relación afectiva en el marco de una misma lucha.

\section{Lorenzo y su cansancio}

Lorenzo contaba, en ese momento, con una terapeuta que iba todos los días a su domicilio, con una Fonoaudióloga, una Terapista Ocupacional y una Acompañante Terapéutico que iban con él a la escuela. A su vez, iba va a comenzar natación, estaba chocho. Un año iba a equinoterapia, iba a natación, a las terapias, y la doctora les dijo que se enfoquen en las terapias. Lorenzo se duerme en las terapias, está cansado. Aquí puedo advertir lo que plantea Angelino Alfonsina cuando refiere a aquellas prácticas de la rehabilitación que, luego del diagnóstico médico, forman parte de la vida del niño y de su familia. Toda práctica, todo juego será terapéutico y en clave de tratamiento (...) nadar será hidroterapia; andar a caballo, equinoterapia; jugar será ludoterapia, y así infinitamente. La misma autora sostiene que en esa línea, traccionan las obras sociales y los propios profesionales dejando de lado a las figuras significativas afectivamente con quienes podrían imaginar alternativas de atención y autocuidado. Así, salen de la escena de la dinámica cotidiana del niño diagnosticado los hermanos, amigos, vecinos y demás referencias afectivas posibilitantes o habilitantes (2014:200).

De manera similar, me apropio de los aportes de Gisela Untoglich (2009), quién haciendo referencia a Bleichmar (1998), nos dice que el diagnóstico funciona como una brújula que orienta el camino y las acciones a seguir, para el profesional, pero no pueden aplastar al sujeto. Aquí, me parece interesante hacer mención a Indiana Vallejos, quién habla acerca de una naturalización de la necesidad del diagnóstico y del control médico para la organización de la vida cotidiana que instala prescripciones para la crianza de los niños con discapa- 
cidad, como también otras prescripciones en torno a la organización de lo cotidiano (2009:205).

En este sentido, María Eugenia me contó que para Lorenzo resultaba estresante dejar sus cosas recreativas y pasar a terapia y sonriendo me dijo que cuando él deje de enchincharse antes de las terapias me va a decir "hoy empezamos bien la terapia sin protestar". En este sentido recupero nuevamente las palabras de Alfonsina Angelino cuando manifiesta que,

para dar sostén a lo cotidiano entran en escena una multiplicidad de prácticas profesionales de la rehabilitación que se ocuparan de cuidar a ese niño o niña (...) el ritmo cotidiano se estructura en torno a una grilla de actividades determinadas por los profesionales, que transforman a los padres en llevadores y buscadores de los hijos a los distintos centros de atención o consultorios. Quedan suspendidos en su papel de decisores y solo ejecutan lo que los profesionales indican (2014:200).

En relación a ello, M. Eugenia referenció acerca de una carpeta paralela, que ella tenía de las terapias y de la escuela, y, que cuando la neuróloga se la vio le dijo "borra esa carpeta". Lorenzo ¿cuándo va a jugar? fue a partir de esa recomendación que ella comenzó a estar más relajada y entendió que Lorenzo estaba cansado de las terapias que fueron muy estructuradas desde que él era chiquito.

Luego de presentar a Lorenzo, su diagnóstico y parte de su tratamiento y el rol que cumple su madre en la organización y distribución de su vida. Me propuse pensar en María Eugenia, en su cotidianeidad, en sus tiempos y sus espacios.

Ella es docente de Educación Musical, y tal como lo expresara, podría trabajar hasta en tres lugares, pero renunció a un cargo de titular por Lorenzo. Por consiguiente, al momento de la investigación, se dedicaba exclusivamente a su cuidado, tal es así que había abandonado su única actividad recreativa que era correr en la costanera de Santa Fe, allí sentía una liberación, pero, por otro lado, sentía que abandonaba a Lorenzo. La culpa que sentía no le permitía dejar a Lorenzo y, a todos los lugares que él va, va acompañado por ella. En tal sentido, las terapeutas trataban que ella se aleje, pero ella 
estaba ahí, atenta a todos los pedidos de él. Nunca lo dejó solo, ni en los cumpleaños infantiles. Esto coincide nuevamente a lo que plantea Alfonsina Angelino respecto de que

La ideología de la normalidad no solo construye y legitima representaciones hegemónicas acerca de la discapacidad como enfermedad crónica, que necesita de cuidados permanentes, sino que también construye y legitima un continuum entre mujer-madre-cuidado como esencialmente femenino y doméstico. Si las mujeres como madres son las responsables de sus hijos pequeños en el caso de madres con hijos con discapacidad esta esencialización de lo femenino se tensiona con otra: la esencialización de la discapacidad (2014:193).

\section{Mamás Agendas}

Quizás sea Marina la madre que demostró ser las más organizada y estructurada al destacar a cada momento la distribución de tareas en la agenda de Tobías, pero, en los relatos de Laura y María Eugenia también pude percibir cómo las actividades de Leandro y Lorenzo configuraban también su cotidianeidad. Como Laura, quién me contó las diferentes lógicas y estrategias que realizaba para enseñarle a Leandro las leyes y señales de tránsito para que a corto plazo él pueda manejarse solo en la Ciudad.

Por su parte María Eugenia preocupada porque Lorenzo no entendía o no percibía que si él no respetaba las leyes de tránsito los autos lo iban a chocar, llevó a cabo una estrategia con los juguetes del niño. Lorenzo tenía dos años y medio cuando ella decidió tirarle con un camión de juguete para que él comprendiera lo peligroso de salir a la calle sin mirar. En palabras de María Eugenia "me dolió en el alma, asi le dije, así Lorenzo te van a hacer los autos". Rememorando, ella mencionó que es una experiencia horrorosa pero Lorenzo lo pudo entender.

Por otra parte, y respecto a las rutinas, me dijo que no se las puede cambiar, incluso el fin de semana "que no tenés ganas de hacer estructura" él se levanta y le da de comer a Moni (su gata) y al pez. Tampoco así puede apagar la alarma, con un nene con autismo no podes dormirte, ya que las actividades apresuradas generan estrés y 
te volvés loca. En este sentido, Rossana Reguillo haciendo mención a Giddens, nos dice que,

La vida cotidiana es simultáneamente «habilitante y constrictiva». Sus mecanismos y lógicas de operación, al ser rutinizadas, constriñen a los actores sociales, les imponen unos límites, fijan unos márgenes y unos modos de operación, sin embargo, hay una franja de indeterminación relativa que deja espacio para la «improvisación», lo mismo para hacer frente a situaciones novedosas como para incorporar, normalizando, discursos y prácticas que penetran desde el orden social, los mundos de la vida (2000:79).

Como en los relatos de estas mujeres que aun teniendo una vida cotidiana estructurada se encontraban con un espacio para la improvisación y vivencia de nuevas experiencias.

\section{Pensar y Actuar Colectivamente}

María Eugenia enfatizó en la idea de ayudar al otro, de escuchar, de ayudar, de compartir momentos para que estas personas no pasen por lo que ella pasó, para aliviarles el camino a muchas madres, reconociendo el estrés por el que ellas transitan, admitiendo que los problemas se resuelven, pero aparecen otros y, resaltando la necesidad de informarse y formarse respecto del Autismo. Con respecto a ello, M. Eugenia formaba parte desde el año 2013 del Grupo TGD Padres. Para ella, resulta imprescindible abrirle la cabeza al papá que no le pasa nada si va al neurólogo o a la fonoaudióloga. Por este motivo, en la entrevista, refiriéndose a un evento de Concientización sobre Autismo realizado en junio de 2016 en la Peatonal de la Ciudad de Santa Fe, donde muchas familias se acercaron para obtener información, ella se preguntó: ¿dónde están que no están en los grupos? no están en ningún grupo y no saben qué hacer, ¿qué será de la vida de esa familia? con el estrés que implica todo esto y, haciendo referencia al carnet de discapacidad que tenés que esperar, tenés miedo de la junta evaluadora, que no te den el carnet, es horrible, reflexiona que ellos como padres, no pueden pasar por ese estrés, porque el carnet es tan valioso, porque tenés la Obra Social, te cubren las 
terapias, no pensas en si podes comprar un auto a mitad de precio, lo que vos queres es que entren todas las terapias y hay cosas que no entran y no podemos estar sufriendo.

Lo propuesto por María Eugenia fue compartido también por Laura quién, junto a otras mamás, estuvo desde los inicios del Grupo TGD Padres, que data de julio del 2011. El objetivo principal del grupo respondió a la necesidad de reunir otros padres que estén pasando por la misma situación, compartir experiencias e intercambiar información, en palabras de Juan Vasen (2011), la inclusión de niños en programas de cobertura y acciones de cuidado se hace a través de un etiquetamiento que legitima la gravedad del cuadro y la pertinencia de cierto tipos de abordajes, lo cual moviliza múltiples recursos institucionales, que genera en todo el mundo el desarrollo de organizaciones por profesionales o padres que, accediendo a internet se han informado y ejercen una fuerte presión, un Lobby para lograr reconocimientos y coberturas específicas, tal es el caso del Grupo TGD Padres, que no solo lucha por normativas jurídicas como ser la Ley 13.328 de Protección Integral de las Personas con Trastornos del Espectro Autista (TEA) y/o Trastornos Generalizados de Desarrollo (TGD), sino que a su vez promueve a través de eventos concientizadores que se hable de AUTISMO.

En relación a los integrantes del grupo Laura expresó que ellos están por una lucha en común y no por una lucha por cuestiones de ego, haciendo mención con esto último a que los problemas al interior del grupo se deben a conflictos personales entre ellos mismos y no específicamente por la causa que los convoca; puesto que en este momento no solo se encontraban organizando la jornada de la cual hice mención, sino también, la asistencia a un Simposio Latinoamericano de Autismo, organizado por la FUNDACIÓN PANAACEA, que se llevaría a cabo en Buenos Aires. Además, junto a otras madres, Laura concurriría al Primer Congreso Internacional de Autismo, a realizarse en Bariloche el 17 y 18 de marzo de 2017. Me parece interesante resaltar estas actividades que como madre de un niño diagnosticado realizaba Laura, porque al decir de Angelino (2014) el querer saber mucho, acerca de estos diagnósticos, responde al cuidado, para cui- 
darlo mejor. En ese sentido, la formación de Laura es parte de su Vida Cotidiana, siendo necesario resaltar que ella no solo se ocupa del diagnóstico y tratamiento de su hijo sino que también, es una referente dentro del Grupo, que orienta y guía a otros padres que recientemente se han encontrado con que su hijo o hija ha sido diagnosticado, les comparte información, los orienta y ayuda en la búsqueda de profesionales, los escucha, los acompaña y los aconseja en esta experiencia de discapacidad.

Conforme lo descripto a lo largo de estas carillas pude afirmar que el Grupo TGD padres manifestó su compromiso, actitud y lealtad en la lucha que se despliega a nivel mundial, esa que durante el año 2017 se expresó bajo el lema "Rompamos juntos barreras por el autismo". Por consiguiente, desde la Confederación Autismo España y la Confederación Española de Autismo (FESPAU), en coordinación con Autismo Europa, promueven una campaña de concienciación para dar a conocer este trastorno a la sociedad y atraer la atención sobre las necesidades y la realidad de las personas con Trastorno del Espectro del Autismo (TEA) y sus familias. Advierten que las personas con autismo se enfrentan a numerosas barreras a la hora de disfrutar de sus derechos fundamentales y de formar parte plenamente de la comunidad. Para el movimiento asociativo del autismo es muy importante que la sociedad entienda cuáles son las barreras a las que se enfrentan las personas con TEA porque eso permitirá una mejor adaptación a sus necesidades y reforzará la inclusión de estas personas en todos los ámbitos de la sociedad.

En relación a ello, tanto Marina, Laura como María Eugenia directa o indirectamente en sus relatos refieren a dichas consideraciones, específicamente cuando hacen mención a la Escuela y a su necesidad de informarle tanto a los docentes como a los padres de sus compañeros/as, la situación de su hijo, porque en palabras de Marina cuánto más gente sepa y conozca más mito se van a derribar y más fácil se le va a hacer a él, en relación a Tobías porque, según ella no es lo mismo que vos digas "mira este gurí es un caprichoso" a que vos entiendas realmente que a él le está pasando algo o que reacciona de tal manera por algo en particular. Por su parte Laura expresa que no 
solo es el alumno el que tiene que adaptarse al docente, sino que el docente se tiene que adaptar al alumno también porque no todos son iguales, a Leandro le es más fácil una materia y la otra es difícil y, así todos los chicos, entonces primero tenés que conocer al alumno, te lleve el tiempo que te lleve sino, no sos docente, quédate en tu casa... De igual modo encuentro similitud en la última entrevista realizada a María Eugenia, quién enuncia lo que pasó con las primarias, refiriéndose a las Escuelas por las que transitó Lorenzo. Ella expresa que las maestras no le daban ni bolilla, ni a Lorenzo ni al grupo, pero que ella a través de la presentación de diferentes notas en las que aclaraba que dicha docente no era competente, logró que la cambiaran, sin olvidar esos dos años de llanto, estrés, quejas y notas por las que tuvo que pasar para que ello suceda.

Estas mujeres no solo atraviesan las luchas cotidianas como madres de niños discapacitados, sino que representan la lucha cotidiana colectivizada en la que modifican no solo su vida sino también la de otras familias que, a través de la experiencia se van convirtiendo conjuntamente en un círculo de contención, compromiso y cuidado que tiene como objetivo una mejor calidad de vida para aquellas personas diagnosticadas con TGD y/o TEA y para su entorno.

\section{Conclusiones}

Los encuentros con estas mujeres me permitieron conocer ese mundo de la vida a partir de los relatos. Esa vida cotidiana que se modifica a partir del diagnóstico tuvo como centralidad la estructuración a la que es sometido el niño en todas sus actividades, dado que el diagnóstico significa un punto de inflexión en la organización de la vida cotidiana, porque es a partir de él que ésta se vuelve más estructurada, reglada y, fundamentalmente terapéutica porque, el niño o niña diagnosticado con TGD y/o TEA tiene actividades, no solo terapéuticas pautadas y regladas sino también aquellas que corresponden al juego y la recreación y, en este sentido, los otros integrantes de la familia se adaptan a la distribución de tareas propuestas por la agenda del niño o niña. 
A través de los relatos de las madres pude conocer y significar la comprensión específica que ellas tienen acerca de la situación diagnóstica de sus hijos, al mismo tiempo que las experiencias, emociones y actitudes que tuvieron no solo frente al diagnóstico de su hijo/a sino también frente a las circunstancias que se les presentaron en sus prácticas cotidianas a partir de la noticia del mismo. En este sentido, tanto Marina como Laura y María Eugenia aluden a las búsquedas y recorridos que realizaron en la emergencia del diagnóstico y, una vez que sus hijos fueron diagnosticados ambas comenzaron con diferentes trayectos para obtener los mejores tratamientos, como así también el establecimiento educativo acorde a las necesidades de su hijo/a. Por otro lado, las tres hacen mención a las diferentes estrategias que llevan a cabo para trasmitirle a sus hijos aquellas prácticas que forman parte de la cotidianeidad de las personas.

Fueron las entrevistas en profundidad las que facilitaron las interacciones sostenidas con las madres, pero, además, también prioricé otros espacios que me concedieron una nueva mirada a los relatos de estas tres mujeres, como ser reuniones y jornadas al interior del Grupo TGD padres. En este sentido, la conformación de grupos, el compartir experiencias, el informarse, el acompañarse y el cuidarse entre sí, forma parte de la cotidianeidad en cada una de las familias dado que son ellas las que ejercen presión para el reconocimiento de derechos de sus hijos e hijas. Al mismo tiempo que impulsan la reglamentación de leyes, vigilan a diario el alcance y cumplimiento de las mismas. En relación a ello y, si bien a lo largo del trabajo hice referencia a la Ley 13.328, sancionada en la Provincia de Santa Fe, de Diagnóstico Precoz, Tratamiento, Integración, Inclusión Social y Protección Integral de Personas con TEA y/o TGD, es necesario mencionar que durante el tiempo transcurrido desde que inicié la investigación, en la Provincia Entre Ríos se retomó el debate en torno la protección integral y la inclusión plena de los niños y niñas con diagnósticos de TEA y/o TGD. En este sentido, se propone avanzar en una norma que contemple las múltiples dimensiones y dificultades por las que atraviesan familiares y personas con TGD y/o TEA. 
En relación a los tratamientos de rehabilitación en el escenario de la vida cotidiana, es a partir del diagnóstico que se modifica la misma, su estructura ahora tiene nuevas actividades que responden a los tratamientos propuestos por los médicos para lograr la rehabilitación de sus hijos, pero, antes de ahondar en este punto, cabe un inciso respecto de la noticia del diagnóstico.

De las tres entrevistadas, solo una de ellas, afirma que nunca se dio cuenta y que fue una maestra la que la alertó sobre algunas características en su hijo, por su parte las otras dos se dieron cuenta antes, una porque su hijo no les prestaba atención y la otra simplemente por el hecho de que cuando éste nació no se prendía de la teta y si lo hacía no la miraba. Marina afirma que a ellos no los puso mal el diagnostico porque éste también es una respuesta a cosas que no entendes, en tal sentido solo sintieron que deberían trabajar más, siendo ese el impacto que les generó la confirmación del diagnóstico. Por su parte Laura manifiesta que cuando el médico les dijo "TGD" ellos quedaron helados y que desde ese día comenzaron la búsqueda de profesionales para la rehabilitación de su hijo. También, resalta la actitud que tuvo el médico hacia ellos la cual potenció la incertidumbre que les generaba esta noticia. Por último, para María Eugenia si bien no era una noticia nueva ya que ella ya lo sabía, cuándo te dicen diagnóstico se te derrumbó la vida, se te derrumbó todo, manifestando la necesidad de organizarlo a él para después organizarte vos.

Luego del diagnóstico, las tres mujeres aluden a la búsqueda de los tratamientos de rehabilitación propuestos por los médicos confirmando a su vez que todos los juegos y actividades realizadas por el niño tienen como propósito la superación de diferentes situaciones. Asimismo, ambas reconocen al tiempo como determinante en la recuperación, quizás a ello responde la necesidad de un cuidado exclusivo y minucioso que tiene como objetivo la autonomía de sus hijos. Es así que, durante los relatos ninguna de las madres hizo alusión a sus tiempos libres, pudiendo concluir que la agenda de Tobías se convierte en la agenda de Marina, la de Leandro en la de Laura y la de Lorenzo en la de María Eugenia. Además, si bien las tres hacen mención a los padres de los niños quedan comprobado el rol que ellas adquieren al 
interior de la familia. En este sentido, a lo largo de este trabajo quedó demostrado que las madres como vitales partícipes en las familias con niños diagnosticados con TGD y/o TEA son las que están atentas y expectantes de cada detalle en la vida de sus hijos y aquí me parece pertinente retomar lo planteado por Alfonsina Angelino (2014) cuando alude a los distintos actores que participan en el cuidado de las personas discapacitadas, afirmando que, en el cuidado de la familia se coloca en el centro a las mujeres como responsables principales e ineludibles del bienestar de sus integrantes. Por consiguiente,

La ideología de la normalidad no solo construye y legitima representaciones acerca de la discapacidad como enfermedad crónica, que necesita de cuidados permanentes, sino que también construye y legitima un continuum entre mujer-madrecuidado como esencialmente femenino y doméstico. Si las mujeres como madres, son las responsables del cuidado de sus hijos pequeños, en el caso de las madres de hijos con discapacidad esta esencialización de lo femenino se tensiona con otra: la esencialización de la discapacidad (2014:193).

En este sentido, cabe señalar que tanto Marina como Laura se dedican exclusivamente a las tareas cotidianas y especialmente a las de Tobías y Leandro, mientras que María Eugenia si bien es docente y trabaja fuera de su casa organiza su vida en función de Lorenzo. Es decir, en el momento en que él concurre a la escuela ella da clases, afirmando que podría trabajar hasta en tres lugares, pero prioriza pasar más tiempo con su hijo.

En el relato de Marina puedo advertir que su cotidianeidad, es decir sus prácticas, estrategias, espacios y temporalidades están organizadas y estructuradas detalladamente para que el tratamiento de Tobías funcione efectivamente tal y como le sugieren los médicos. En efecto, ella es la encargada de organizar y distribuir las actividades del niño, de acompañarlo no solo a las terapias sino a todos aquellos lugares al que éste concurra. Y no solo ello, sino que es también Marina quién procura que se utilicen las imágenes que constituyen las agendas del niño, manifestando que, si bien para su utilización tienen que trabajar más, en realidad es una pavada, porque la agen- 
da es la misma todos los días y solo cambian ciertas actividades. Puedo sugerir que en el discurso de Marina se manifiesta implícitamente su necesidad de cuidar a Tobías, su intención de protegerlo. Puedo indicar también que la organización de la agenda de Tobías es parte de la cotidianeidad en la familia, y que, tal como lo mencionó al inicio del encuentro, el diagnóstico de Tobías no los puso mal, solo sintieron que tendrían que trabajar más. Aquí, se evidencia, una vez más, la dedicación de Marina al cuidado de su hijo, él todo el tiempo tiene que estar con alguien, necesita estimulación. Es por este motivo que ella deja de trabajar afuera de su casa, para convertirse en la principal responsable en lograr el bienestar de su hijo. El tiempo de Marina es el tiempo de Tobías y viceversa. Un tiempo laborioso y exclusivo. Un tiempo de trabajo entre la familia, las terapeutas y la escuela, un tiempo entre imágenes y agendas.

En el caso de Laura, a diferencia de Marina y María Eugenia, si bien intenta proteger a su hijo procura también que éste adquiera autonomía y libertad en cada uno de sus actos para que a corto plazo pueda ser independiente. Explícitamente en su relato puedo advertir el sentimiento de angustia cuando junto a su marido tuvieron la noticia del diagnóstico, desconcierto que se acrecienta día a día desde su separación. Laura se siente sola y reclama constantemente acciones por parte del padre de sus hijos dado que es ella quién se ocupa en acompañar a cada uno en su formación, más precisamente a Leandro a quién lleva y trae en cada una de sus actividades. Por consiguiente, es a partir del diagnóstico de Leandro que su vida se modifica, es decir el tiempo y el espacio constitutivos de la cotidianeidad se organizan, de allí en más, de manera diferente y, si bien la vida cotidiana en esta familia se modificó, es Laura quién instaura el tiempo y el espacio de la misma, organizando los tránsitos y recorridos en las vidas de sus hijos. Asimismo, también es ella quien en su diario transcurrir procura formarse e interiorizarse en los nuevos avances en el diagnóstico de su hijo, para luego incorporarlos en las prácticas cotidianas porque, al decir de Alfonsina Angelino existe una asociación naturalizada entre cuidado y mujeres que, pareciera radicalizarse si 
hablamos de mujeres madres que cuidan hijos/hijas discapacitados, y en relación a ello la autora afirma:

ese llegar a saber todo y más que los médicos definen una forma del cuidar en estas mujeres y también les permite tomar otras posiciones frente al poder medico/ profesional. Discutir y disputar conocimientos, cambiar de profesionales. Hacer otras consultas, repartir análisis, todo suele evidenciarse como el modo de poner en suspenso las certezas esgrimidas (...) se marca la necesidad de acceso a la información y la necesidad de que como madres se socialicen los recorridos, trayectos, los mejores tratamientos, los profesionales más humanizados (2014:197).

En el relato de Laura es posible comprender de manera detallada la vida cotidiana de su familia, analizar las experiencias y sentimientos respecto de las luchas en las rutinas cotidianas, como así también las que corresponden a aquellas que lleva a cabo al interior del Grupo TGD padres Santa Fe. Con Laura entable una relación de conversación más espontánea, ella se adueñó de la narración tanto singular como colectivamente. Se (re) conoció a sí misma como una madre comprensiva y luchadora. Más aun, completo este relato advirtiendo en Laura una madre protectora y combativa, como así también espontánea y animada.

En relación a María Eugenia, se puede advertir, no solo la urgencia con la cual indagó respecto de los tratamientos de rehabilitación para su hijo, sino también el lugar central que éstos ocupan en el escenario de su vida cotidiana porque, aun admitiendo que (su) Lorenzo está cansado responde a cada una de las actividades sugeridas por los médicos. Como resultado, ella manifiesta que para Lorenzo es estresante dejar sus actividades recreativas y pasar a las terapias que, desde sus inicios fueron muy estructuradas. Es María Eugenia la que habla del estrés por el que atravesó cuando su hijo fue diagnosticado, alegando que todas pasan por ese camino en el cual te caes pero luego te levantas y te curas. Es aquí donde puedo percibir que el estado al que ella refiere concierne a las diversas situaciones que se presentan en su cotidianidad y que son inherentes a la vida de su hijo, por consiguiente, ella también está cansada. También llora. La vida cotidiana 
de María Eugenia es la vida cotidiana de Lorenzo, esto queda evidenciado cuando hace referencia a su trabajo como docente y, cuando manifiesta que las terapeutas le suplican que se aleje del niño. Aquí puedo advertir que para María Eugenia proteger y cuidar a Lorenzo es el papel central en su vida y es por ello que renuncia no solo a uno de sus trabajos sino también a la única actividad recreativa que tenía antes de la llegada de su hijo. En su testimonio alude a la sensación de culpa que siente al dejar a Lorenzo y es por ello que hasta cuando el niño se encuentra con su padre ella lo acompaña. A decir verdad, y tal como ella lo expresara, es la familia la que atraviesa las distintas experiencias cotidianas, pero a lo largo de esta construcción se puede observar que es ella quien responde no solo física sino psíquicamente a cada una de las demandas que forman parte de la protección a su hijo. Ella es una madre organizada, sensible y divertida que venera a cada momento por el bienestar de su hijo. El tiempo de María Eugenia es el tiempo de la protección a (su) Lorenzo. Allí sentimientos, esfuerzos, éxitos y fracasos se articulan para ser de esa figura madre, una figura omnipresente.

Tal como se desprende durante los relatos, la vida cotidiana en las familias con niños o niñas diagnosticados con Trastorno Generalizado del Desarrollo y/o Trastorno del Espectro Autista se modificó a partir del diagnóstico, más específicamente la vida cotidiana de las mujeres-madres de niños o niñas discapacitados quienes no solo están en el centro del cuidado, sino que también son las principales participes en la lucha por el reconocimiento de los Derechos de sus hijos. Por consiguiente, la conformación de grupos responde a la necesidad de ayudar a otras madres para que no pasen por lo mismo, pero, a su vez es la actividad que ellas realizan para sentirse acompañadas y conectadas en esta experiencia de la discapacidad, donde ponen en obra sus sentidos, deseos, capacidades, ideas y sentimientos en la búsqueda de la igualdad, la justicia y la ciudadanía. 


\section{Referencias bibliográficas}

Angelina, M. A. (2014) Mujeres intensamente habitadas. Ética del cuidado y discapacidad. Entre Ríos, Fundación La Hendija. 2014.

Lindon, A. La vida cotidiana y su espacio-temporalidad. México: Anthropos, 2000.

Rosato, A., Angelino, Ma. A. (Ed.). (2009) Discapacidad e ideología de la normalidad. Desnaturalizar el déficit. Buenos Aires: Noveduc.

Rosato, A. et al. (2006) Proyecto de Investigación: Discapacidad y Exclusión Social: un abordaje interdisciplinario. Facultad de Trabajo Social, Universidad Nacional de Entre Ríos.

Sistema Argentino de Información Jurídica. (2013) Ley $N^{\circ} 13.328$ de "Diagnóstico Precoz, Tratamiento, Integración, Inclusión Social y Protección Integral de Personas con Trastornos del Espectro Autista (T.E.A.) y/o Trastornos Generalizados del Desarrollo (T.G.D.). SAIJ, Santa fe, Argentina. Recuperado de http://test.e-legis-ar.msal.gov.ar/ leisref/public/showAct.php?id=21856

Taylor S. J., y Bodgan R. (2000) Introducción a los métodos cualitativos de investigación. Barcelona: Paidós.

Untoiglich, G. (2009) Patologías Actuales en la Infancia. El Trabajo con los padres en la Clínica con Niños. Buenos Aires: Noveduc

Vain, P. y Rosato, A. (Ed.). (2015) La construcción Social de la normalidad. Alteridades, diferencias y diversidad. Buenos Aires: Noveduc.

Vasen, J. (2011) Una nueva epidemia de nombres impropios. El DSM-V invade la infancia en la clínica y las aulas. Buenos Aires: Noveduc.

Recepción: 29/05/2019

Aceptación: 22/07/2019 